\title{
Pelatihan Desain Grafis dan Multimedia di Sekolah Menengah Kejuruhan Persatuan Guru Republik Indonesia Banyuputih Situbondo
}

\author{
Sony Panca Budiarto \\ Sekolah Tinggi Ilmu Komputer PGRI Banyuwangi \\ sonystikombanyuwangi@gmail.com
}

\begin{abstract}
Inside the millennial and digital era today, the design world is experiencing very rapid improvement. In this example, the more youthful technology or students want to be equipped with information of photo layout and multimedia as a provision of competencies, hoping that once they graduate, college students can right away work or open commercial enterprise opportunities. going through a totally fast competition within the world of labor, the sector of education is required to equip graduates each smooth capabilities and abilities. photograph and multimedia design education sports are focused on product design training using Corel Draw X7. the supply of image design education substances due to photo design encompasses all fields that require verbal language translators to be visually designed for textual content and pix in various media guides in an effort to deliver the message to the communicant as correctly as feasible. by means of studying photograph design and multimedia it's far expected that students of class XII of SMK PGRI Banyuputih-Situbondo can form skills after graduating from faculty to compete inside the outdoor international with a view to achieve success and capable, increase creativity and highquality of work in order that it's miles beneficial for them and society.
\end{abstract}

Keywords: Graphic design; Multimedia; Corel draw X7; SMK PGRI banyuputih

\begin{abstract}
Abstrak
Dalam era milenial dan digital saat ini, dunia desain mengalami perkembangan yang sangat pesat. Dalam hal ini, generasi muda atau siswa perlu dibekali ilmu tentang desain grafis dan multimedia sebagai bekal keterampilan, harapannya ketika sudah lulus para siswa dapat langsung bekerja atau membuka peluang usaha. Menghadapi persaingan dunia kerja yang sangat pesat, dunia pendidikan dituntut untuk membekali lulusan baik secara softskill maupun hardskill. Kegiatan pelatihan desain Grafis dan multimedia yang dilakukan difokuskan pada pelatihan desain produk menggunakan Corel Draw X7. Pemberian materi pelatihan desain grafis dikarenakan desain grafis melingkupi segala bidang yang membutuhkan penerjemah bahasa verbal menjadi perancangan secara visual terhadap teks dan gambar pada berbagai media publikasi guna menyampaikan pesan kepada komunikan se-efektif mungkin. Dengan mempelajari desain grafis dan multimedia diharapkan para siswa kelas XII SMK PGRI Banyuputih-Situbondo dapat terbentuk skill setelah lulus sekolah untuk berkompetisi di dunia luar agar menjadi sukses dan kompeten, meningkatkan kreativitas dan kualitas karya sehingga berguna bagi mereka dan masyarakat.
\end{abstract}

Kata Kunci: Desain grafis; Multimedia; Corel draw x7; SMK PGRI Banyuputih

\section{A. PENDAHULUAN}


Sekolah Menengah Kejuruhan Persatuan Guru Republik Indonesia Banyuputih atau disingkat SMK PGRI Banyuputih adalah sekolah menengah kejuruhan swasta yang terletak di jalan Pandean Wonorejo, Kecamatan Banyuputih Kabupaten Situbondo Provinsi Jawa Timur. Melihat perkembangan zaman dan kemajuan teknologi pihak sekolah memandang perlu adanya bekal keterampilan tambahan bagi siswa kelas XII di SMK PGRI Banyuputih sebelum mereka lulus dari sekolah. Keterampilan dan bekal tambahan yang dapat diaplikasikan langsung ketika lulus sekolah. Bedasarkan latar belakang masalah dan analisis situasi, teridentifikasi beberapa hasil permasalahan mitra yaitu siswa calon lulusan dari SMK PGRI Banyuputih perlu diberi bekal ilmu keterampilan tambahan salah satunya adalah keterampilan tentang desain grafis dan multimedia. Desain grafis dan multimedia dapat didefinisikan "aplikasi dari keterampilan seni dan komunikasi untuk kebutuhan bisnis dan industri“.Aplikasi aplikasi ini dapat meliputi periklanan dan penjualan produk, menciptakan identitas visual untuk institusi, produk dan perusahaan, dan lingkungan grafis, desain informasi, dan secara visual menyempurnakan pesan dalam publikasi.

Dengan dibekali materi desain grafis sebelum lulus diharapkan para siswa atau siswi dari SMK PGRI Banyuputih terbentuk skill mereka untuk berkompetisi di dunia luar agar menjadi suskses dan kompeten. Materi pelajaran desain grafis yang akan diberikan disini adalah CorelDraw X7. Penggunaan aplikasi CorelDraw X7 dikarenakan coreldraw tidak mengalami perubahan radikal dari satu versi ke versi berikutnya, sehingga informasi dalam modul yang disediakan untuk pelatihan masih bisa digunakan. Perbedaan yang ada adalah kemampuan baru pada toolbar dan menu baru (suharmawan, 2016).

CorelDraw X7 adalah salah satu aplikasi yang menunjang pembuatan desain grafis dalam bentuk vektor. Corel Draw merupakan program pengolah desain grafis yang familier dan paling diminati dikalangan desain grafis. Program ini dapat digunakan dengan mudah karena terdapat tool-tool maupun efek yang menghasilkan berbagai bentuk desain yang inovatif dan ekspresif dengan dilengkapi komposisi warna yang bagus, serta adanya tool untuk membuat objek yang unik dan kreatif.

Desain grafis atau rancang grafis adalah proses komunikasi menggunakan elemen visual, seperti tulisan, bentuk, dan gambar yang dimaksudkan untuk menciptakan persepsi akan suatu pesan yang disampaikan. Desain grafis pada awalnya diterapkan untuk media-media statis, seperti buku, majalah, dan brosur. Sebagai tambahan, sejalan dengan perkembangan zaman, desain grafis juga diterapkan dalam media elektronik, yang sering kali disebut sebagai desain interaktif atau desain multimedia.

Batas dimensi pun telah berubah seiring perkembangan pemikiran tentang desain. Desain grafis bisa diterapkan menjadi sebuah desain lingkungan yang mencakup pengolahan ruang (Suparno, 2016). Unsur dalam desain grafis sama seperti unsur dasar dalam disiplin desain lainnya. Unsur-unsur tersebut (termasuk shape, bentuk (form), tekstur, garis, ruang dan warna, membentuk prinsip-prinsip dasar desain visual. Prinsipprinsip tersebut seperti keseimbangan (balance), ritme (rhytm), tekanan (emphasis), proporsi (proportion) dan kesatuan (unity), kemudian membentuk aspek structural komposisi yang lebih luas (Arumi \& Burhanuddin, 2018) 
Sebagai wujud ikut serta dalam mencerdaskan Kehidupan bangsa, maka dalam kegiatan pengabdian kepada masyarakat ini mengadakan Pelatihan Desain Grafis dan Multimedia (Sari \& dkk, 2016). Kegiatan ini dilaksanakan di SMK PGRI Banyuputih Situbondo.

Pelatihan adalah suatu proses pembelajaran yang memperbanyak praktek dibandingkan teori yang dilakukan pelatih secara mendiri ataupun berkelompok untuk meningkatkan kemampuan dari individu ataupun kelompok. Tujuan dari pelatihan adalah individu maupun kelompok yang dilatih mempunyai penguasaan ketrampilan yang dapat dikuasai. Jenis pelatihan ada pelatihan wacana, ketrampilan, dan soft skill. Sedangkan ciri pelatihan antara lain terdapatnya suatu proses untuk meningkatkan ketrampilan yang dimiliki, materi yang disampaikan merupakan ketrampilan tertentu yang diperlukan, pelatihan dalam jangka waktu tertentu, dan proses pelatihannya dilakukan dengan mempelajari dan mempraktekkan sehingga menjadi kebiasaan. (Budi, 2013)

Kegiatan pelatihan sangat penting karena bermanfaat guna menambah pengetahuan atau keterampilan terutama bagi yang mempersiapkan diri memasuki lapangan pekerjaan (Anggun, 2013). Beberapa manfaat yang diperoleh dari program pelatihan diantaranya adalah (Simamora, 2004) :

1) Meningkatkan kualitas dan kuantitas produktivitas.

2) Mengurangi waktu belajar yang diperlukan untuk mencapai standar kinerja yang dapat diterima.

3) Membentuk sikap, loyalitas, dan kerjasama yang lebih menguntungkan.

4) Memenuhi kebutuhan perencanaan sumber daya manusia.

5) Mengurangi frekuensi dan biaya kecelakaan kerja.
6) Membatu dalam peningkatan dan pegembangan pribadi mereka.

Dengan adanya pelatihan ini kami mengharapkan para murid memiliki bekal keterampilan desain grafis dan multimedia sehingga dapat lebih optimal dalam memanfaatkan komputer setelah lulus sekolah, dapat bersaing di dunia kerja ataupun membuka jasa wirausaha desain grafis atau percetakan.

\section{B. PELAKSAAAN DAN METODE}

Kegiatan Pengabdian Kepada Masyarakat ini dilaksanakan pada bulan Februari 2018 dan kegiatan ini dilaksanakan di SMK PGRI Banyuputih Situbondo. Kegiatan dilaksanakan selama 2 hari mulai tanggal 3 dan 4 Februari 2018 di Laboratorium Komputer SMK PGRI Banyuputih Situbondo, diikuti oleh 35 murid kelas XII.

Kegiatan pelatihan ini dimaksudkan untuk menambah keterampilan para murid kelas XII di SMK PGRI Banyuputih Situbondo dalam bidang design grafis dengan cara praktikum secara langsung. Kegiatan Pelatihan diawali dengan pembukaan dan arahan pentingnya mengikuti pelatihan desain grafis dan Multimedia oleh Bapak Sutedjo, S.Pd., M.M, selaku Kepala Sekolah SMK PGRI Banyuputih Situbondo, kegiatan selanjutnya diserahkan kepada dosen dari Sekolah Tinggi Ilmu Komputer Persatuan Guru Republik Indonesia Banyuwangi (STIKOM PGRI Banyuwangi) yang melakukan kegiatan pengabdian kepada masyarakat.

Metode kegiatan pengabdian kepada masyarakat ini dilakukan oleh 1(satu) orang dosen yang turun langsung dalam penyampaian materi dan dibantu beberapa guru pada saat proses pendampingan praktikum. Hari pertama kegiatan pelatihan 
desain grafis dan multimedia di SMK PGRI Banyuputih, adalah memberi penjelasan tentang pentingnya desain grafis dilanjutkan dengan pengenalan aplikasi desain grafis dan multimedia yang akan digunakan selama pelatihan yaitu menggunakan aplikasi CorelDraw X7, dilakukan oleh dosen pengabdi dari STIKOM PGRI Banyuwangi.

Selanjutnya dosen pengabdi memberikan tutorial praktik, pengenalan tentang tool-tools yang ada di CorelDraw X7 beserta fungsi dan kegunaannya. Siswa memperhatikan melalui layar LCD projector dan modul materi pelatihan yang sudah diberikan. Penyampaian materi dilakukan selama 45menit selanjutnya setiap siswa dianjurkan untuk praktikum secara mandiri dengan mengikuti panduan dari pemateri dan modul pelatihan dengan system pendampingan.

Pada hari kedua, untuk mencapai target dan tujuan diadakannya pelatihan ini. Maka dilaksanakan evaluasi kegiatan dengan cara setiap peserta diberikan tugas membuat desain banner dan brosur penerimaan peserta didik baru SMK PGRI Banyuputih sesuai dengan ide dan kreatifitas masing-masing siswa. Selama proses evaluasi berlangsung, siswa yang mengalami kesulitan dalam mengerjakan tugas, dapat langsung bertanya kepada dosen pengabdi atau guru pendamping. Selama kegiatan pelatihan berlangsung dosen pengabdi tidak lupa memberikan motivasi kepada para siswa supaya mengembangkan kreatifitas dalam bidang desain grafis.

\section{HASIL DAN PEMBAHASAN}

Sebelum mendapat pelatihan desain grafis CorelDraw X7, keterampilan desain grafis para siswa kelas XII SMK PGRI Banyuputih Situbondo kurang optimal, pada umumnya siswa hanya dapat membuat objek dasar, memberi warna atau background hasilnya masih ada yang kurang rapih. Siswa belom bisa menambahkan teks, mengatur jenis, ukuran dan warna huruf serta meletakkan diposisi yang diingikan. Hal ini menunjukkan keterampilan desain grafis siswa dalam menggunakan aplikasi coreldraw X7 cukup rendah dan membutuhkan latihan-latihan yang tepat untuk meningkatkan kemampuan desain grafis mereka.

Kegiatan pengabdian kepada masyarakat di SMK PGRI Banyuputih untuk siswa kelas XII diberikan dengan maksud agar siswa memiliki bekal keterampilan dibidang multimedia, harapannya siswa mampu memanfaatkan teknologi menjadi sebuah media penyampaian informasi melalui desain, contoh banner, brosur, undangan dll.

Materi yang diberikan pada kegiatan pengabdian kepada masyarakat oleh Dosen S1 Teknik Informatika dari STIKOM PGRI Banyuwangi, adalah: Pengenalan CorelDraw $\mathrm{X} 7$, disertai penjelasan tentang pentingnya belajar desain grafis, fungsi dan kegunaan coreldraw. Kemudian pengenalan tool-tool yang ada pada aplikasi coreldraw, dilanjutkan praktik membuat logo SMK PGRI Banyuputih dan banner. Untuk pendalaman materi yakni siswa diharuskan membuat desain brosur atau banner penerimaan siswa baru di SMK PGRI Banyuputih sesuai dengan kreasi mereka masing-masing.

Pada Gambar 1 memperlihatkan proses kegiatan pelatihan yang diikuti oleh para siswa. Pada kegiatan ini proses pemberian materi dilakukan oleh Dosen pengabdian masyarakat dari STIKOM PGRI Banyuwangi dibantu oleh beberapa orang guru dari SMK PGRI Banyuputih. 


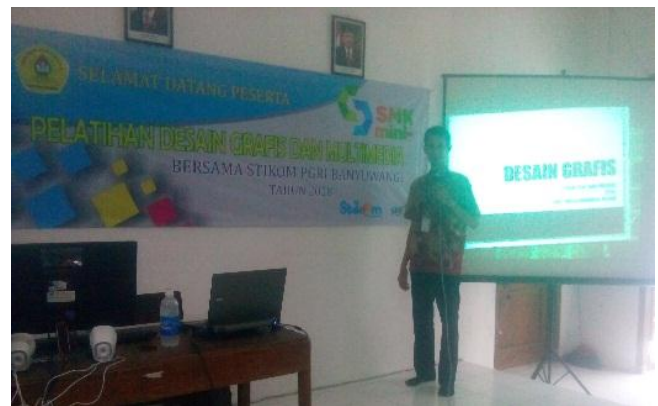

Gambar 1. Pemberian Materi Kepada Peserta

Siswa memperhatikan materi yang dipraktikkan oleh instruktur melalui layar LCD dan modul pelatihan yang diberikan, seperti terlihat pada Gambar 2.

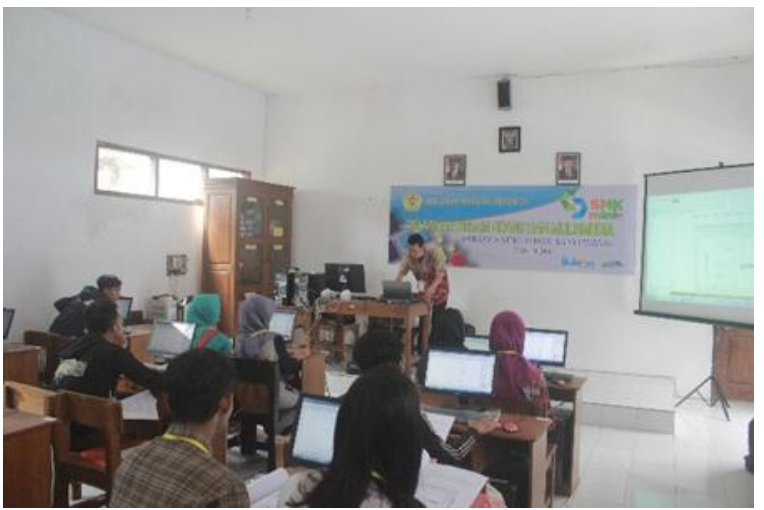

Gambar 2. Instruktur menjelaskan tentang CorelDraw X7 menggunakan alat bantu LCD.

Pendampingan praktikum dalam kegiatan pelatihan diperlukan agar para siswa benar-benar paham dalam mengaplikasikan materi yang diberikan. Pada Gambar 3 memperlihatkan proses pendampingan peserta kegiatan.

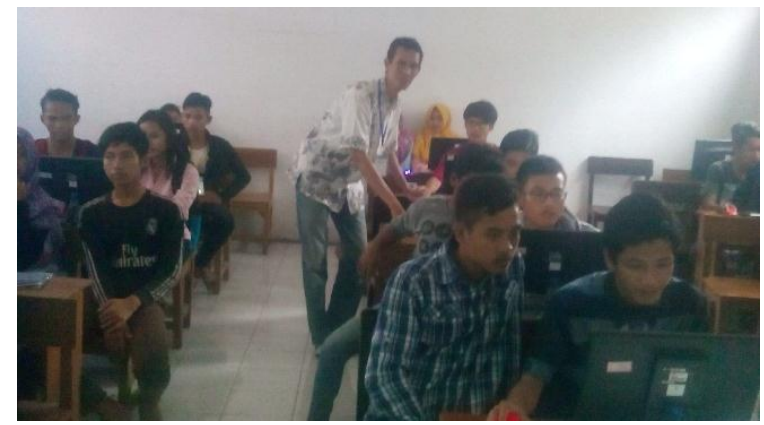

Gambar 3. Proses Pendampingan Peserta Kegiatan
Pada proses pendampingan ini siswa yang menemui kesulitan dalam proses praktikum diarahkan dan dibimbing secara langsung, harapannya siswa lebih cepat paham dan mengerti.

Hampir seluruh siswa sangat antusias mendapatkan materi ini, dikarenakan mereka baru pertama kali belajar materi desain grafis. Hal ini dapat dilihat pada saat proses pendampingan, seperti pada Gambar 4.

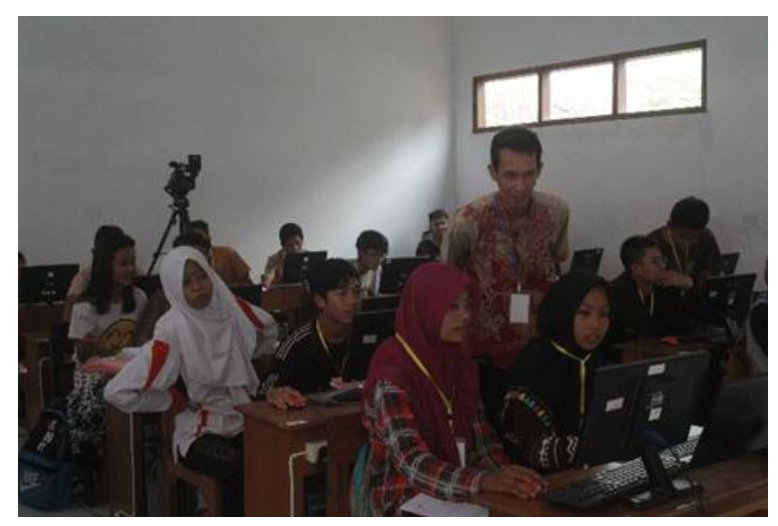

Gambar 4. Pendampingan secara langsung

Setelah dilakukan pelatihan dan pendampingan secara intensif terdapat peningkatan terhadap keterampilan desain grafis para siswa kelas XII di SMK PGRI Banyuputih Situbondo. Terdapat peningkatan variasi objek dasar yang dibuat oleh para siswa dengan tingkat kerapihan yang baik, objek dasar yang dihasilkan tampak lebih proporsional. Para siswa sudah memahami langkah-langkah dalam memberikan variasi warna dan background. Pemberian variasi warna dan background sudah memberikan efek keindahan pada objek yang dibuat. Para siswa bukan hanya dapat membuat tulisan, namun juga mampu mengedit jenis dan ukuran tulisan, sehingga mampu memperkuat keindahan dan kreatifitas objek yang didesain oleh para siswa.

Hasilnya para siswa sudah mampu meniru dan membuat desain logo, banner dan 
undangan sesuai dengan kreasi masingmasing.

\section{PENUTUP}

\section{Simpulan}

Kegiatan Pelatihan berjalan lancar dan tertib, Kepala Sekolah dan para siswa sangat antusias dengan adanya pelatihan desain grafis dan multimedia dari Dosen STIKOM PGRI Banyuwangi. Para siswa menyambut positif kegiatan yang telah dilakukan, mereka mengharapkan adanya kegiatan-kegiatan serupa yang sifatnya menambah keterampilan dan ilmu yang tidak didapatkan pada pelajaran di kelas.

Siswa kelas XII di SMK PGRI Banyuputih sangat merasakan manfaat dari adanya pelatihan Desain Grafis ini, hal ini dibuktikan dengan hasil kreasi produk desain grafis yang dihasilkan sangat variatif dan orisinil.

Pada era modern saat ini, ilmu desain sangat penting bagi kehidupan. Dengan bekal kemampuan desain grafis dan multimedia diharapkan para generasi muda atau lulusan sekolah dapat membuka peluang usaha industri kreatif dan menjadi entrepreneurship (Pranoto, 2015).

\section{Saran}

Para siswa harus sering berlatih menggunakan aplikasi CorelDraw X7 untuk mengasah kemampuan dan keterampilan dalam hal desain grafis. Pihak sekolah sebisa mungkin menambahkan materi desain grafis dan multimedia pada kegiatan akademik sekolah.

Kegiatan pelatihan seperti ini sangat penting terutama bagi siswa untuk menunjang skill sehingga dapat diterapkan pada masyarakat nantinya, harapannya kegiatan pengabdian kepada masyarakat berupa pelatihan desain grafis dan multimedia agar ditingkatkan dan diagendakan untuk dilakukan di seluruh SMA/SMK/MA di kabupaten Banyuwangi secara bergantian oleh STIKOM PGRI Banyuwangi.

\section{Ucapan Terima Kasih}

Tim Pengabdian Kepada Masyarakat STIKOM PGRI Banyuwangi mengucapkan terima kasih kepada :

1. Bapak H. Chairul Anam, S.Kom, M.M selaku Ketua STIKOM PGRI Banyuwangi.

2. Bapak Sutedjo, S.Pd., M.M selaku Kepala Sekolah SMK PGRI Banyuputih Situbondo.

3. LP3M STIKOM PGRI Banyuwangi

4. Guru dan Staff Laboratorium Komputer SMK PGRI Banyuputih.

5. Siswa dan siswi kelas XII SMK PGRI Banyuputih Situbondo.

Atas kesempatan yang telah diberikan kepada Dosen STIKOM PGRI Banyuwangi untuk melakukan Pelatihan Desain Grafis dan Multimedia kepada siswa kelas XII.

\section{E. DAFTAR PUSTAKA}

Anggun, 2013. Konsep Pelatihan dan Pengembangan. [Online] Available at: https://www.goenable.wordpress.com/ tag/tujuan-dan-manfaat-pelatihan/

Arumi, E. R. \& Burhanuddin, A., 2018. Peningkatan Kreatifitas Siswa Sekolah Menengah Pertama Dengan Pelatihan Corel Draw, Magelang: Universitas Muhammadiyah Magelang.

Budi, S., 2013. Skema dan Mekanisme Pelatihan Panduan Penyelenggaraan 
Pelatihan. Jakarta: Yayasan Terumbu Karang Indonesia (TERANGI).

Pranoto, A., 2015. Pentingnya Desain Bagi Generasi Muda, jakarta: makalah.

Sari, M. \& dkk, 2016. Pelatihan Design Grafis CorelDraw X4 Sebagai Penunjang Pembelajaran Bagi Guru Pada SMAN 1 Sungai Tabuk. AlIkhlas, pp. 34-38.

Simamora, H., 2004. Manajemen Sumber Daya. Cetakan Pertama, Edisi Kedua. Yogyakarta: STIE YKPN.

Suharmawan, 2016. Modul Materi Corel Draw X7, Jakarta: Academia.edu.

Suparno, S., 2016. Kreasi Desain Grafis Inovatif dengan Corel Draw. Jakarta: PT Elex Media Komputindo. 